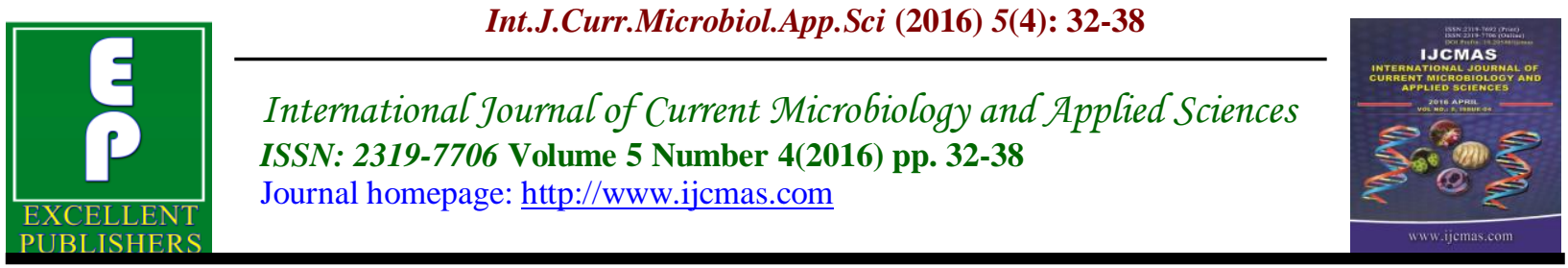

Original Research Article

http://dx.doi.org/10.20546/ijcmas.2016.504.006

\title{
In-Vivo Evaluation of Competitive Parasitic Ability and Rhizosphere Colonisation of Different Trichoderma Isolates
}

\author{
Monika Singh', O P Sharma², Someshwar Bhagat ${ }^{2}$ and Neetu Pandey ${ }^{1}$ \\ ${ }^{1}$ Department of Biotechnology, Mewar University, Chittorgarh, Rajasthan-312901, India \\ ${ }^{2}$ ICAR-NCIPM, IARI Pusa, New Delhi-110012, India \\ *Corresponding author
}

Keywords

Rhizosphere colonisation, Competitive parasitic ability, Trichoderma, Sclerotinia sclerotiorum, chickpea (Cicer arietinum L.).

\section{Article Info}

Accepted:

08 March 2016

Available Online:

10 April 2016

\section{A B S T R A C T}

The rhizosphere competence of Trichoderma isolates was conducted with chickpea, using natural and sterilized soils of Neemrana, Rajasthan. The rhizosphere population of Trichoderma increased at an increasing rate from 15 to 30 DAS and 30 to 45 DAS and thereafter increased but at a decreasing rate and finally declined after 45 DAS, in both soil types. There was appreciable more number of rhizosphere populations of antagonists in rhizosphere soil of test crop observed at 45 DAS than at 15 and 30 DAS. Competitive parasitic ability was conducted in two different soil conditions, viz., natural and steam sterilized soil collected from three states. Under natural soil of Uttar Pradesh, the isolate UP:Bam003 and MP:Kha030 appeared most efficient in their competitive parasitic ability against sclerotia of $S$. sclerotiorum, whereas the isolate MS:Mar016 was with intermediate effect and the isolate UP:Kus008 were poor competitive colonizer on sclerotia of S. sclerotiorum. Considering the conidial form of inoculum, the isolate UP:Bam003 appeared most efficient colonizer of sclerotia of $S$. sclerotiorum, whereas UP:Kus008 exhibited as least colonizer and isolate MP:Kha030 and MS:Mar016 showed intermediate colonizing ability of sclerotia. While considering the chlamydospores form of inoculum, the isolate UP:Bam003 was best competitive colonizer of sclerotia of test pathogen showing $91.5 \%$ colonizing ability.

\section{Introduction}

The ability of Trichoderma species to colonize and establish themselves in the rhizosphere is of crucial importance to achieve efficient control of phytopathogens around the seeds and the roots (Baker 1991; Papavizas 1985). Some Trichoderma strains, described as rhizosphere competent and can cause an asymptomatic infection of roots, behave as endophytes, colonizing the root epidermis and outer cortical layers and release bioactive molecules, responsible for increased plant resistance to various biotic and abiotic stresses through induced or acquired systemic resistance (McLean et al., 2005; Shoresh et al., 2010). The competitive parasitic ability of Trichoderma spp. using 
sclerotia as live baits of several pathogens has been studied (Bhagat and Pan, 2009; Roy and Pan, 2005b) but few researches has been done on Sclerotinia sclerotiorum. Therefore, the aim of this study is to depict the rhizosphere colonisation and competitive parasitic ability of Trichoderma isolates in chickpea rhizosphere using sclerotia of $S$. sclerotiorum as live bait.

\section{Materials and Methods}

\section{Competitive Parasitic Ability of Trichoderma Isolates}

This experiment was conducted in two types of soils viz., natural and sterilized soils of Neemrana, Rajasthan to assess the ecological adaptability of Trichoderma spp. $200 \mathrm{~g}$ air dried (natural and sterilized soil) was mixed thoroughly with mycelial, conidial and chlamydospores inocula of test isolates of Trichoderma separately, moisture holding capacity of each soil type was adjusted to $50 \%$ and fitted into the earthen cups $(100 \mathrm{ml})$.

25 sclerotia of $S$. sclerotiorum were buried $0.5-2.0 \mathrm{~cm}$ deep, covered with perforated aluminum foil and incubated at $28 \pm 1^{\circ} \mathrm{C}$ for 7 days.

The sclerotia of $S$. sclerotiorum were harvested separately by floatation and sieving method (Rodriguez-Kabana et al., 1974) and plated on modified Trichoderma selective medium (TSM) after surface sterilization with $1.0 \%$ sodium hypochlorite solution for 2-3 min. and air dried. The petridishes seeded with sclerotia of $S$. sclerotiorum, were incubated at $28 \pm 1^{\circ} \mathrm{C}$ for 7 days and the sclerotia with colonization by Trichoderma spp. in each treatment were recorded. The percentage colonization of sclerotia of both pathogens by Trichoderma spp. was calculated by dividing the number of sclerotia yielding Trichoderma by total number of sclerotia seeded in the petridishes.

\section{Rhizosphere Colonization of Trichoderma Isolates}

The rhizosphere competence of test isolates of Trichoderma was conducted with chickpea (Cicer arietinum L.), using natural and sterilized soils of Neemrana, Rajasthan. Two kg potting mixture of soil (natural and sterilized soil) and farm yard manure (2:1 $\mathrm{v} / \mathrm{v})$ was mixed thoroughly with $20 \mathrm{~g}$ of wheat bran + mustard cake $(20 \%)$ formulation of Trichoderma isolates $\left(1 \times 10^{8}\right.$ $\mathrm{cfu} / \mathrm{g}$ of product), MHC of the potting mixture was adjusted to $50 \%$ and filled into the earthen pots.

Twenty five seeds of chickpea were sown per pot. The experiment was replicated four times and seeds of test crop were allowed to germinate. The pots were supplied with irrigation water whenever required to maintain the MHC of potting mixture to $50 \%$. The rhizosphere soil was collected by gently uprooting the test crops and brushing the soil adhered to roots after 15 DAS. The observation was repeated at 15 days interval and the data were recorded upto 45 DAS. The rhizosphere soil collected was mixed thoroughly and the rhizosphere population of Trichoderma spp. was estimated by soil dilution technique (Dhingra and Sinclair, 1995). Ten mg of soil samples of each isolate-crop combination was suspended in $10 \mathrm{ml}$ sterilized distilled water. The suspension was serially diluted upto $10^{8}$ and $1 \mathrm{ml}$ each of these aliquot was plated on modified TSM with five replications. The inoculated Petridishes were incubated at $28 \pm 1^{\circ} \mathrm{C}$ for 7 days and the number of colony forming units per $g$ of rhizosphere soil for each isolate was counted. The total number of cfu/g of rhizosphere soil was the 
rhizosphere population of Trichoderma spp.

\section{Results and Discussion}

\section{Competitive Parasitic Ability}

The data on competitive parasitic ability of four isolates of Trichoderma sp. viz. UP:Bam003 (T. asperellum), UP:Kus008 (T. viride) MP:Kha030 (T. koningiopsis) and MS:Mar016 (T. viride) against sclerotia of $S$. sclerotiorum have been presented in Figure 1. The experiments were conducted in two different soil conditions, viz., natural and steam sterilized soil, collected from Bambawad (UP), Hamirpur (UP), Parbhani (Maharashtra) and Narsingpur (MP).

Under natural soil of Uttar Pradesh, the isolate UP:Bam003 and MP:Kha030 appeared most efficient in their competitive parasitic ability against sclerotia of $S$. sclerotiorum, whereas the isolate MS:Mar016 was with intermediate effect and the isolate UP:Kus008 were poor competitive colonizer on sclerotia of $S$. sclerotiorum. Considering the conidial form of inoculum, the isolate UP:Bam003 appeared most efficient colonizer of sclerotia of $S$. sclerotiorum than other isolates tested under natural soil of UP, whereas UP:Kus008 exhibited as least colonizer and isolate MP:Kha030 and MS:Mar016 showed intermediate colonizing ability of sclerotia.

While considering the chlamydospores form of inoculum, the isolate UP:Bam003 was best competitive colonizer of sclerotia of test pathogen showing $91.5 \%$ colonizing ability, whereas MS:Mar016 (58.25\%) resulted into least aggressive requiring high inoculum level under natural soil of Maharashtra. The other antagonistic isolates were found with intermediate effect under natural soils of UP and MP.
In steam sterilized soil, the situation changed further regardless of form of inocula or isolates of Trichoderma itself, where they required very low level of inocula (either mycelia or conidia or chlamydospores form) than that in the natural soil condition. Surprisingly, the isolate UP:Kus008 showed the maximum competitive colonizing ability in mycelial form of inoculum whereas the isolate MS:Mar016 and UP:Bam003 was with intermediate effect and the isolate MP:Kha033 were poor competitive colonizer on sclerotia of S. sclerotiorum. Isolate MS:Mar016 exhibited highest percent colonization conidial form of inoculum and UP:Bam003 showed in chlamydospore form of inoculum. The possible justification of this study could be credited to the fact that the natural soil often does not allow introduced biocontrol agents to perform well due to some abiotic and biotic factors (Knudsen and Bin, 1990 and Bae and Knudsen, 2005). Soil solarisation and sterilization upsets the ecosystem to the extent that it may allow proliferation of Trichoderma spp. Present results corroborated with the findings of Lewis and Papavizas (1985) where they suggested that mycelial inoculum was better than conidial inoculum, for soil application and chlamydospres were less sensitive to biotic and abiotic stresses.

\section{Rhizosphere Colonization}

The perusal of entire results on rhizosphere colonization of Trichoderma spp. from MP, UP and Maharashtra, under natural and sterilized soils indicated that all isolates of Trichoderma significantly colonized the rhizosphere of chickpea crop tested compared to control. The rhizosphere population of Trichoderma increased at an increasing rate from 15 to $30 \mathrm{DAS}$ and 30 to 45 DAS and thereafter increased but at a 
decreasing rate and finally declined after 45 DAS, in both soil types. But there was appreciable more number of rhizosphere populations of antagonists in rhizosphere soil of test crop were observed at 45 DAS than that at 15 and 30 DAS.

Figure.1 Percentage Colonization by Trichoderma Isolates in Three Different Inoculums Levels in Natural and Sterilized Soil

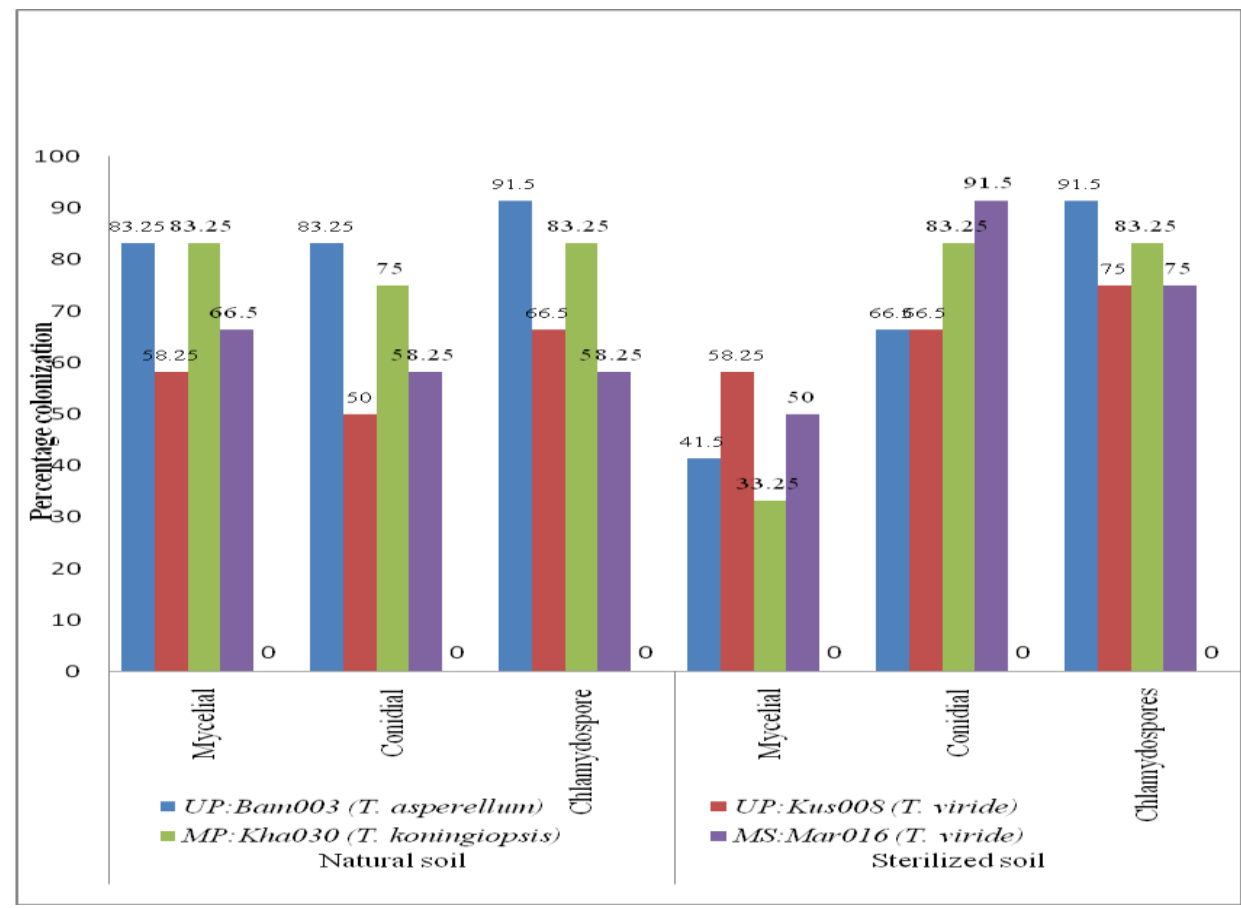

Figure.2 Rhizosphere Colonization by Trichoderma Isolates in Terms of their CFU Count (1x 108 cfu/g Soil)

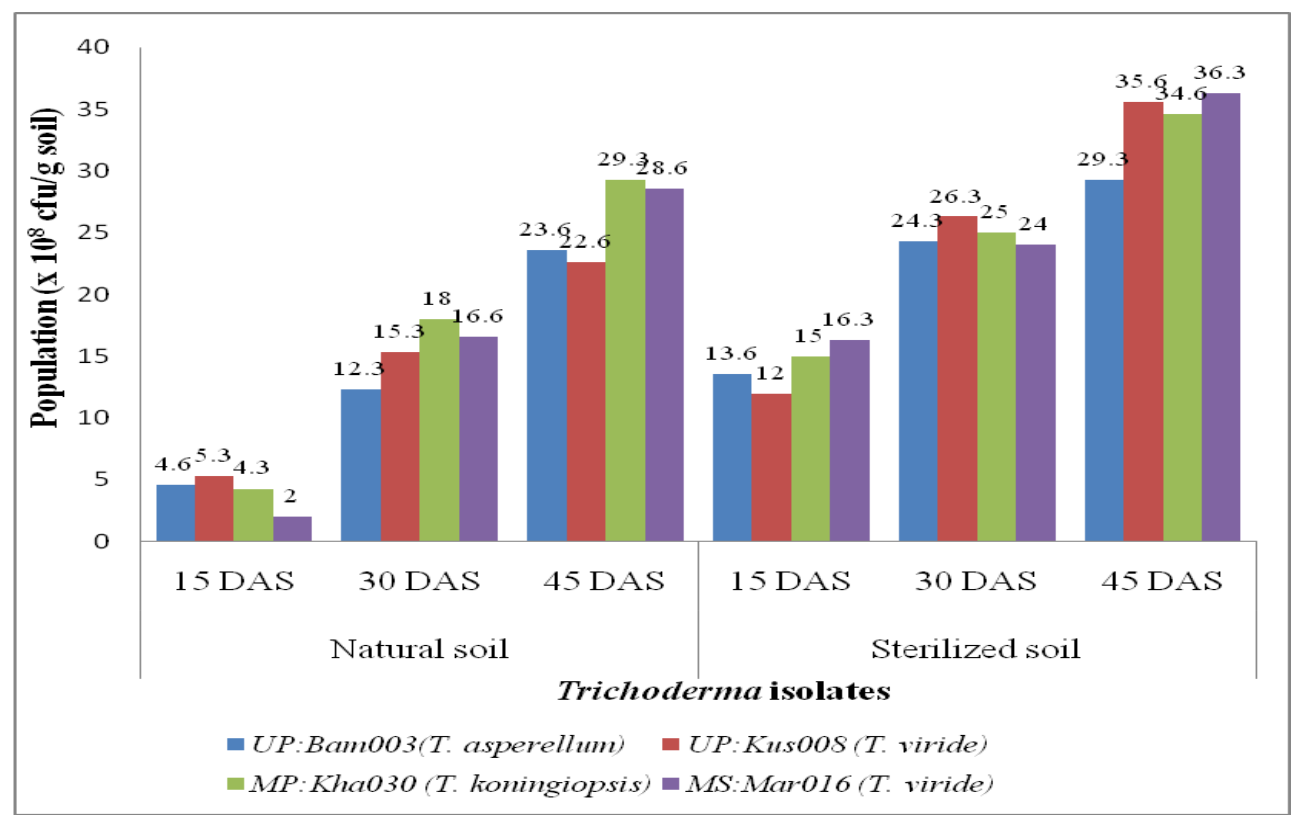


Plate.1 Trichoderma Isolated from Rhizosphere Soil of Chickpea to Check the Presence of Root Colonization by Trichoderma in Natural and Sterilized Soil after Soil Incorporation at 15, 30 and 45 Days of Sowing (DAS)

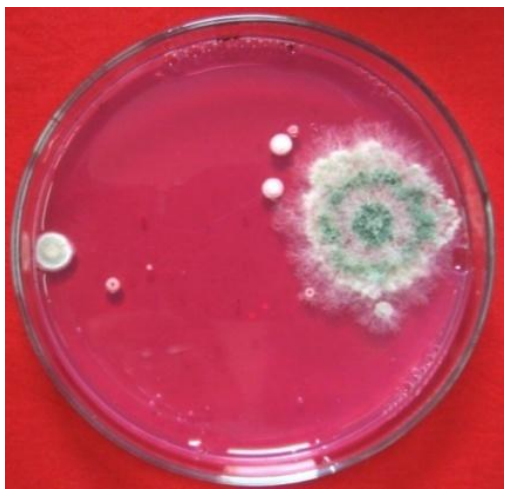

15 DAS

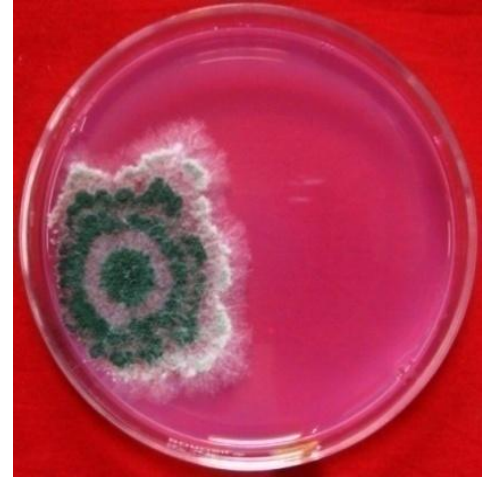

15 DAS

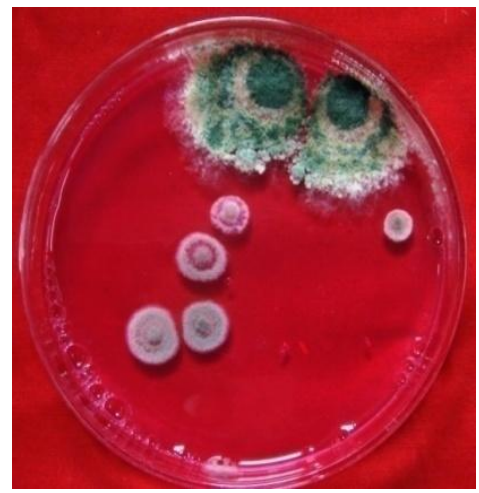

30 DAS

Natural soil

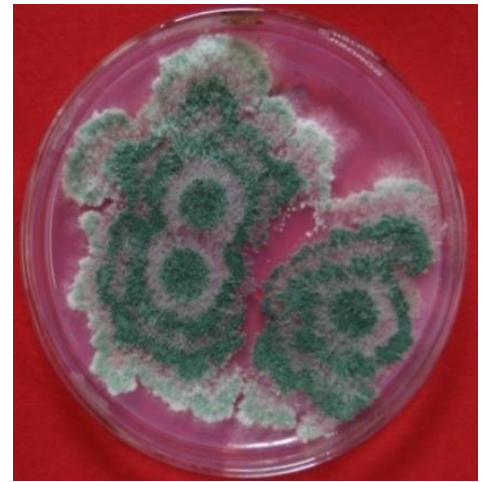

30 DAS

Sterilized soil

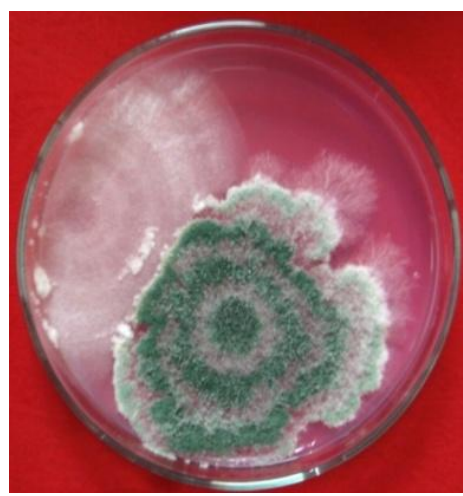

45 DAS

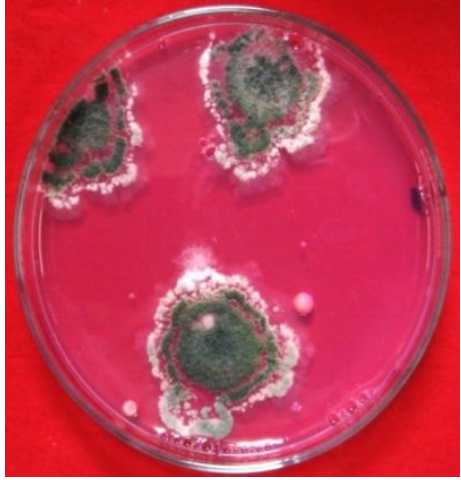

45 DAS
In chickpea (Figure 2), highest rhizosphere population of Trichoderma was recorded with the isolate MP:Kha030 (18 and $29.3 \mathrm{x}$ $10^{8} \mathrm{cfu} / \mathrm{g}$ of soil at 30 and 45 DAS), followed by MS:Mar016 (16.6 and $28.6 \mathrm{x}$ $10^{8} \mathrm{cfu} / \mathrm{g}$, at 30 and 45 DAS), UP:Kus008 (15.3and $22.6 \times 10^{8} \mathrm{cfu} / \mathrm{g}$ at 30 and 45 DAS) and UP:Bam003 (12.3 and $23.6 \times 10^{8} \mathrm{cfu} / \mathrm{g}$ at 30 and 45 DAS) in natural soil of Rajasthan, whereas the rhizosphere population of 24 and $36.3 \times 10^{8} \mathrm{cfu} / \mathrm{g}$ of soil at 30 and 45 DAS in chickpea was recorded with MS:Mar016 in sterilized soil of Neemrana, Rajasthan which also appeared as most efficient rhizosphere colonizer in chickpea (Plate 15). The rhizosphere populations of antagonist were less in natural soil compared to sterilized soil. The isolate MS:Mar016 were the most efficient colonizer under both natural and sterilised soils of Neemrana. The isolate UP:Kus008 was recorded with least rhizosphere population in chickpea rhizosphere under both natural and sterilized soils and rest isolates were with intermediate category in view of their rhizosphere competence in chickpea.

Sharma et al. (2010) reported that high population of Trichoderma $\left(2 \times 10^{6}\right.$ to $80 \mathrm{x}$ $10^{6} \mathrm{cfu} / \mathrm{g}$ colony population) between flowering and pre-harvesting was observed in the samples collected from the rhizospheric soil samples. The rhizosphere 
competent isolate of Trichoderma spp. was found to produce diffusible metabolites in the rhizosphere which actively influenced the growth of Trichoderma-colonized plant due to their action as plant growth regulators (auxin and/or auxin-like compound) (Vinale et al., 2008a,b).

The effectiveness of Trichoderma as seed treatment is probably determined not only by their biocontrol qualities but also by their abilities to multiply in the rhizosphere when applied to soil and their PGPR properties. In present findings there were increase in the rhizosphere population of Trichoderma spp. with the advancement of crop age upto 45 DAS and thereafter the population declined marginally. Benitez et al. (2004) reported that Trichoderma has a strong capacity to mobilize and take up soil nutrients, thus making it more efficient and competitive than many other soil microbes. The present findings suggested that there was less rhizosphere population of Trichoderma spp. when they were applied to crops which were grown in natural soil as compared to sterilized soil. The possible explanation of these findings may be due to ecological specificity of Trichoderma spp. (Bae and Knudsen, 2005; Papavizas, 1985) and existence of microbial competition which does not allow flourishing the antagonist in that situation (Whipps, 2001).

\section{References}

Bae, Y.S., Knudsen., G.R. 2005. Soil microbial biomass on growth and biocontrol efficacy of Trichoderma harzianum. Biol. Control, 32: 236242.

Baker, R. 1991. Induction of rhizosphere competence in the biocontrol fungus Trichoderma, In: The Rhizosphere and Plant Growth. Eds., Keister, D.L. and Cregan,
P.B., No. 14, pp. 221-228, Beltsville Symposia in Agricultural Research, Beltsville, M. D., USA.

Benitez, T., Rincon, A.M., Limon, M.C., Codon, A.C. 2004. Biocontrol mechanisms of Trichoderma strains. Int. Microbiol., 7: 249-260.

Bhagat, S., Pan, S. 2009. Comparative ecological behaviour of some preand post-tsunami isolates of Trichoderma harzianum and $T$. viride from Andaman and Nicobar Islands. J. Pl. Protection Sci., 1(1): 34-39.

Dhingra, O.P., Sinclair, J.B. 1995. Basic Plant Pathology Methods, 2nd edn. CRC press, Bocca Raton, America.

Knudsen, G.R., Bin, L. 1990. Effects of temperature, soil moisture, and wheat bran on growth of Trichoderma harzianum from alginate pellets. Phytopathol., 80: 724-727.

Mclean, K.L., Swaminathan, J., Frampton, C.M., Hunt, J.S., Ridgway, H.J., Stewart, A. 2005. Effect of formulation on the rhizosphere competence and biocontrol ability of Trichoderma atroviride C52. Pl. Pathol., 54: 212-218.

Papavizas, G.C. 1985. Biological control of soil borne diseases. Summa Phytopathol., 11: 173-179.

Rodriguez-Kabana, R., Backman, P.A., Wiggins, E.A. 1974. Determination of sclerotial population of Sclerotium rolfsii in soil by a rapid floatation-sieving technique. Phytopathol., 64: 610-615.

Roy, A., Pan, S. 2005b. Competitive parasitic ability and biocontrol potential of mutants of Trichoderma harzianum and Gliocladium virens against Sclerotium rolfsii induced root rot of groundnut. Indian $J$. 
Mycol. Pl. Pathol., 35: 326-33.

Sharma, P., Patel, A.N., Deep, S., Saini, M.K., Jambulkar, P.P., Gangwar, O.P., Prakasham, V. 2010. Field performance of Trichoderma harzianum (TH3) for rhizosphere rabi crops. E-planet, 9(2): 8-13.

Shoresh, M., Harman, G.E., Mastouri, F. 2010. Induced systemic resistance and plant responses to fungal biocontrol agents. Ann. Rev. Phytopathol., 48: 21-43.

Vinale, F., Sivasithamparam, K., Ghisalberti, E.L., Marra, R., Barbetti, M.J., Li, H., Woo, S.L.,
Lorito, M. 2008a. A novel role for Trichoderma secondary metabolites in the interactions with plants. Physiol. Mol. Pl. Pathol., 72: 8086.

Vinale, F., Sivasithamparam, K., Ghisalberti, E.L., Marra, R., Barbetti, M.J., Li, H., Woo, S.L., Lorito, M. 2008b. Trichodermaplant-pathogen interactions. Soil Biol. Biochem., 40: 1-10.

Whipps, J.M. 2001. Microbial interactions and biocontrol in the rhizosphere. J. Experimental Bot., 52: 487-511.

\section{How to cite this article:}

Monika Singh, O.P. Sharma, Someshwar Bhagat and Neetu Pandey. 2016. In-Vivo Evaluation of Competitive Parasitic Ability and Rhizosphere Colonisation of Different Trichoderma Isolates. Int.J.Curr.Microbiol.App.Sci. 5(4): 32-38. doi: http://dx.doi.org/10.20546/ijcmas.2016.504.006 